\title{
Entre "acordos" e "flexibilizações": construção de sentidos sobre o conceito de trabalho no discurso jornalístico
}

\author{
Between "agreements" and "flexibilizations": construction of meanings about the \\ concept of work in journalistic discourse \\ Estevão Eduardo Cavalcante CARMO* \\ Universidade Federal de Pernambuco (UFPE)
}

\begin{abstract}
RESUMO: A proposta geral deste artigo consiste em analisar o processo de (re) categorização do conceito de trabalho no discurso jornalístico, mais especificamente na versão impressa do jornal Folha de S.Paulo. Para tanto, fundamentamo-nos em dois eixos teóricos principais. Primeiro, nos estudos elaborados por Chouliaraki e Fairclough (1999), Fairclough (2001) e Bourdieu (1998) sobre a relação entre o neoliberalismo e o discurso sobre o trabalho. E, ainda, nas reflexões de Koch (2015 [2002]) e Marcuschi (2007) acerca do processo de (re) categorização na linguagem. Analisamos 10 publicações veiculadas na Folha de S.Paulo entre 24 de dezembro de 2016 e 24 de agosto de 2017. O recorte de tempo aplicado compreende o período de apresentação, tramitação e aprovação da reforma trabalhista (PL n 6787/2016) no Congresso Nacional. Ao final da investigação, observamos que as publicações, baseando-se na reforma, constroem discursivamente um conceito de trabalho simétrico e "flexível", ratificando, portanto, o discurso governamental.
\end{abstract}

PALAVRAS-CHAVE: Trabalho. Categorização. Referenciação. Jornalismo.

ABSTRACT: The general purpose of this article is to analyze the process of (re) categorizing the concept of work in journalistic discourse, more specifically in the printed version of the newspaper Folha de S.Paulo. For that, we are based on two main theoretical axes. First, in the studies carried out by Chouliaraki e Fairclough (1999), Fairclough (2001) and Bourdieu (1998) about the relationship between neoliberalism and the discourse about work. And yet, in the theories of Kock (2015 [2002]) e Marcuschi (2007) on the process of (re) categorization in language. We analyzed 10 publications published in Folha de S.Paulo between December 24, 2016 and August 24, 2017. The time cut applied includes the period of presentation, processing and approval of the labor reform (PL n ${ }^{\circ}$ 6787/2016) in the National Congress. At the end of the investigation, we observed that the publications, based on the reform, construct discursively a concept of symmetrical and "flexible" work, ratifying, thus, the governmental discourse.

KEYWORDS: Work. Categorization. Referencing. Journalism.

* Doutorando em Letras/Linguística pelo Programa de Pós-Graduação em Letras da Universidade Federal de Pernambuco (UFPE). E-mail: estevao.eduardo.cavalcante@gmail.com 


\section{Introdução}

Em 23 de dezembro de 2016, o então presidente do Brasil, Michel Temer (MDB), apresentou à Câmara dos Deputados o projeto de lei (PL) n 6787/2016, mais conhecido como reforma trabalhista. O texto alterava um total de 13 artigos, dos quais 6 constavam na Consolidação das Leis Trabalhistas (CLT) e 7, na Lei de n 6019/1974. A reforma propunha uma série de modificações cujas temáticas se relacionavam, de modo geral, à jornada de trabalho, férias coletivas, relações laborais, multas administrativas e contribuição sindical.

Durante o período em que tramitava no Congresso Nacional, o projeto engendrou discussões e controvérsias nos mais variados setores da sociedade. Dentre eles, o domínio jornalístico, que se debruçou sobre a reforma e suas implicações no cotidiano do trabalhador. A Folha de S.Paulo, um dos jornais de maior circulação no Brasil, veiculou diversas publicações - dos mais diferentes gêneros textuais - sobre a reforma trabalhista, na tentativa de cobrir as votações e modificações pelas quais o texto passava nas duas casas legislativas.

Após muitas alterações, o projeto foi aprovado, no Senado, em 11 de julho de 2017, e sancionado pelo então presidente dois dias depois, em 13 de julho do mesmo ano. De lá até o momento atual, a reforma vem fundamentando decisões judiciais, em todo o país, cujos conflitos sejam de natureza trabalhista. Diante de tal relevância, propomo-nos a analisar, neste estudo, o processo de (re) categorização do conceito de trabalho no domínio jornalístico, e mais especificamente em textos publicados na versão impressa do jornal Folha de S.Paulo.

Optamos pela análise da esfera jornalística por entender que a cobertura realizada pela mídia tradicional contribuiu para a elaboração de um conceito de trabalho específico, durante a apreciação da reforma no Congresso. Os textos examinados neste artigo consistem numa amostragem do corpus ampliado da dissertação de mestrado intitulada "Frame e referenciação nos discursos governamental e jornalístico: investigando o processo de (re) categorização do conceito de trabalho".

Partimos de um quadro teórico que conjuga reflexões da Análise Crítica do Discurso (ACD), sobretudo com os estudos de Fairclough (2001; 2002; 2003), e da 
Linguística de Texto, a partir das considerações sobre o processo de referenciação elaboradas por Koch (2015 [2002]; 2017 [2004]) e Marcuschi (2007).

O trabalho está dividido em quatro tópicos. No primeiro, abordam-se os efeitos do neoliberalismo no discurso sobre o trabalho. No segundo, discute-se brevemente o processo de (re) categorização na linguagem. No terceiro, apresentamos os aspectos metodológicos. No quarto, realizamos a análise dos textos. Por fim, as considerações finais arrolam as principais conclusões da investigação.

\section{O neoliberalismo e o discurso sobre o trabalho}

As mudanças ocorridas no modo de produção ao longo da segunda década do século passado resultaram no que alguns historiadores e sociólogos denominam de Era Pós-Industrial, momento marcado, sobretudo, pela reconfiguração das relações institucionais e interpessoais diante do crescente processo de globalização (CHOULIARAKI; FAIRCLOUGH, 1999). Esse fenômeno acarreou também alterações significativas no campo trabalhista, que, diante da liquidez do mercado, precisou se reajustar conforme as imposições de uma nova economia (BAUMAN, 2001).

Nesse ínterim, o neoliberalismo - entendido aqui enquanto prática e discurso operou fundamentalmente na solidificação e propagação de relações de trabalho precarizadas. Bourdieu (1998) aponta que a agenda neoliberal se assenta no princípio da individualidade, solapando, por conseguinte, quaisquer instituições e interesses de natureza coletiva. Ainda segundo o autor, o programa neoliberal, longe de assistir as necessidades reais da população, exprime tão somente as vontades de um grupo muito específico de atores e instituições, dentre eles acionistas, empresários e operadores financeiros, por exemplo.

Além disso, Bourdieu (1998) ressalta que, a fim de dissimular seus reais propósitos, o neoliberalismo e seus agentes produzem também um discurso cujo objetivo consiste em transformar a agenda neoliberal num fenômeno natural e incorrigível; portanto, impossibilitado de rupturas. Nesse quadro, emerge também o que o sociólogo denomina como o "reino absoluto da flexibilidade".

Chouliaraki e Fairclough (1999) pontuam que novas configurações políticas e econômicas implicam em novos discursos, uma vez que prática social e prática discursiva estão correlacionadas dialeticamente. Desse modo, os autores observam que a 
lógica do neoliberalismo produziu também a lógica da "flexibilidade", sob a qual se assentam discursos que têm como propósito consolidar, reproduzir e ocultar relações institucionais frouxas e precarizadas.

No mundo do trabalho, esse fenômeno se traduz, sobretudo, em contratos trabalhistas que, invariavelmente, põem o trabalhador numa posição frágil e desassistida legal e judicialmente. Bauman (2001, p. 185) pontua que a "flexibilidade" aplicada ao mercado de trabalho "augura um fim do 'emprego como o conhecemos', anunciando em seu lugar o advento do trabalho por contratos de curto prazo, ou sem contratos, posições sem cobertura previdenciária, mas com cláusulas 'até nova ordem"”.

Conforme já mencionado, Bourdieu (1998) adverte que processos como esse são naturalizados e justificados pelo discurso neoliberal, de modo que muitos trabalhadores, inclusive, reproduzem preceitos neoliberais como verdades inquestionáveis. Entendemos, todavia, que a agenda neoliberal pode e deve ser analisada por uma teoria crítica que vise a aprofundar e revelar relações desiguais de poder subjacentes ao discurso econômico produzido pelo neoliberalismo.

Fairclough $(2001 ; 2002 ; 2003)$ salienta que um dos princípios orientadores da Análise Crítica do Discurso (ACD) consiste no estudo minucioso de discursos que operam na manutenção de relações assimétricas de poder, de modo a, em posse desses conhecimentos, provocar rupturas e mudanças na estrutura social. Nessa linha de reflexões, o autor apresenta variados mecanismos linguístico-textuais e discursivos que atuam no encobrimento de desigualdades sociais, como, por exemplo, a tecnologização do discurso. Fundamentando-se na noção de "técnicas de poder" de M. Foucault, Fairclough (2001) comenta e analisa estratégias linguísticas que visam a encobrir relações assimétricas entre atores e instituições sociais.

O conceito de tecnologização do discurso tem relevância fundamental em nossa investigação. No entanto, antes de passarmos aos aspectos metodológicos e à análise, discutimos, a seguir, o processo de (re) categorização na linguagem, ou referenciação, noção imprescindível ao nosso estudo. 


\section{Processos de referenciação: elaborando sentidos no discurso}

Em nossa investigação, afastamo-nos de teorias especulares da linguagem para as quais a língua reflete os elementos, fatos e eventos do mundo. Alinhamo-nos, por outro lado, aos estudos que concebem a língua como um sistema de símbolos que refrata a realidade, na medida em que, ao invés de refletir perfeitamente os elementos do mundo, o (re) constrói continuamente a partir de nossas práticas, crenças e interações (BAKHTIN, 2010 [1929]; MONDADA; DUBOIS, 2005 [1995]). Não se trata, no entanto, de negar a realidade ou relativizar o mundo, conforme ressalta Marcuschi (2007), mas de compreender nossa relação com o mundo mediada pela linguagem e por nossas interações.

Nesse sentido, Marcuschi (2007) ainda observa que referir os elementos, fatos e eventos mundanos não constitui um processo de etiquetagem, no qual ao ser humano seria imputado somente nomear ou etiquetar o mundo conforme suas vontades, como uma espécie de "adão bíblico". O autor entende que tal processo, de outro modo, é atravessado por fenômenos de natureza sociocognitiva, que operam fundamentalmente na elaboração de categorias na linguagem ${ }^{1}$.

Além disso, Marcuschi (2007) aponta que a construção de categorias ocorre intersubjetivamente, dado que os sujeitos cooperam entre si a fim de estabilizarem uma determinada categoria, tendo em conta seus modelos pessoais e culturais de compreensão do mundo. No entanto, no processo categorial, emergem também conflitos, em virtude das diferentes visões e perspectivas dos sujeitos. Nessa linha de reflexões, Mondada e Dubois (2005 [1995], p. 33) observam que "uma categoria lexical impõe um ponto de vista, um domínio semântico de referência, a concorrer com outras categorias sugeridas, e produzindo sentido a partir do contraste com as precedentes".

Desse modo, a título de exemplo, o fenômeno da globalização pode ser categorizado como "necessário" e "positivo" ou como "prejudicial” e "negativo", a depender das opiniões, posicionamentos políticos e grupos sociais dos quais os atores fazem parte. Assim, não cabe designar o processo de categorização linguística como

\footnotetext{
${ }^{1}$ Seguindo as reflexões de Lakoff (1987), entendemos que, embora sejam processos intrinsecamente imbricados, categorização e categorização linguística - referenciação - são fenômenos de natureza distinta, uma vez que este é elaborado no discurso enquanto aquele ocorre a nível sociocognitivo.
} 
referência, mas, antes, como referenciação, dado o seu aspecto múltiplo, fluido, (inter) subjetivo e heterogêneo (MARCUSCHI, 2007; MONDADA; DUBOIS, 2005 [1995]). Além disso, uma vez que a língua não reflete os elementos do mundo, não convém afirmar que o léxico nomeia objetos do mundo, mas, sim, objetos de discurso, dado que tais objetos são elaborados discursivamente (MARCUSCHI, 2006).

Em seu vasto repertório de estudos sobre os mecanismos de referenciação na linguagem, Koch (2017 [2004]; 2015 [2002]; 2014) salienta que a progressão referencial pode ocorrer através de $i$ ) expressões nominais definidas, ii) expressões nominais indefinidas e iii) pronomes ou elipses. Em nossa análise, interessa-nos a referenciação através de expressões nominais definidas a fim de examinar não só o processo de categorização, mas também de recategorização por meio de anáforas.

A anáfora consiste num recurso linguístico-textual que sustenta o referente, retomando-o ao longo do texto em formato de pronomes ou expressões nominais (APÓTHELOZ, 2005 [1995]). Há uma extensa produção científica que aborda os tipos de anáfora $^{2}$, mas, em nossa investigação, concentramo-nos na expressão nominal anafórica direta ou correferencial, isto é, que se refere a um mesmo objeto de discurso. Para exemplificar, observemos o exemplo (1), a seguir, um trecho de uma notícia que integra o corpus deste artigo. Os grifos são nossos.

\section{(1) Após reforma da CLT, gestante e autônomo devem ter nova regra}

Para tentar convencer os senadores a aprovar a reforma trabalhista sem mudanças, o presidente Michel Temer enviou uma carta aos parlamentares para se comprometer a fazer alterações no texto após a tramitação no Congresso Nacional.

$[\ldots]$

(FSP, 29/06/17)

No exemplo (1), é possível observar que vários objetos de discurso são introduzidos. Alguns deles são retomados posteriormente com outras expressões nominais, como, por exemplo, "senadores”, que, mais à frente, é recategorizado com a anáfora "parlamentares". Caso semelhante ocorre com "reforma trabalhista", objeto de discurso retomado, posteriormente, com a expressão anafórica "o texto". Tanto

\footnotetext{
${ }^{2}$ Para um estudo mais aprofundado sobre os tipos de anáfora, ver Cavalcante (2003), Ciulla (2008) e Koch e Marcuschi (1998).
} 
“parlamentares" como “o texto" são considerados anáforas diretas - ou correferenciais -, pois retomam seus respectivos objetos de discurso ao longo do texto.

Conforme assinala Koch (2015 [2002]), mais do que apenas reativar um referente na memória discursiva do leitor, a anáfora direta enseja também conhecimentos compartilhados pelos sujeitos, bem como aponta as opiniões e perspectivas dos interlocutores. Nesse sentido, as anáforas podem ser concebidas como operadores argumentativos, dado que o interlocutor, ao selecionar uma expressão ou item lexical para recategorizar um referente, revela também suas crenças e visões sobre os fatos do mundo.

Fundamentando-nos nesse quadro teórico, passamos agora aos aspectos metodológicos que nortearam a análise dos textos.

\section{Aspectos metodológicos}

Conforme já mencionado na introdução, os textos analisados neste artigo compõem o corpus ampliado de uma dissertação de mestrado cujo propósito foi investigar o processo de (re) categorização do conceito de trabalho nos discursos governamental e jornalístico. Dado que o escopo de um artigo não nos permite a análise de um material mais vasto, optamos por selecionar 10 textos a fim de constituir uma amostragem de alguns dos fenômenos textuais-discursivos observados na dissertação.

As publicações selecionadas foram veiculadas na versão impressa do jornal Folha de S.Paulo, entre 24 de dezembro de 2016 - um dia após a apresentação da reforma trabalhista à Câmara dos Deputados - e 24 de agosto de 2017 - mais de um mês após a sanção do projeto pelo então presidente Michel Temer.

Dividimos, ainda, os 10 textos aqui analisados em dois grupos diferentes. $\mathrm{O}$ primeiro - com cinco publicações - reúne somente textos que, em teoria, não veiculariam explicitamente a opinião do jornalista. Desse modo, nesse primeiro grupo há somente notícias. No segundo grupo, por outro lado, adicionamos cinco textos opinativos, nos quais é possível observar claramente o ponto de vista do autor. Assim, neste grupo, há gêneros diversos, tais como artigos de opinião, análises, colunas e editoriais. 
A seguir, é possível observar os títulos e as datas de publicação dos textos de cada grupo, reunidos nos quadros 1 e 2 .

Quadro 1: títulos e datas de publicação dos textos que integram o grupo das notícias

\begin{tabular}{|c|c|}
\hline Título & \multicolumn{1}{c|}{ Data } \\
\hline Chefe do TST defende autonomia para negociações & $25 / 12 / 2016$ \\
\hline Reforma trabalhista inclui demissão em comum acordo & $13 / 04 / 2017$ \\
\hline Reajustes na crise indicam força de sindicato para negociar acordos & $07 / 05 / 2017$ \\
\hline Após reforma da CLT, gestante e autônomo devem ter nova regra & $29 / 06 / 2017$ \\
\hline Mérito da reforma é reduzir insegurança, dizem especialistas & $13 / 07 / 2017$ \\
\hline
\end{tabular}

Quadro 2: títulos e datas de publicação dos textos que integram o grupo de matérias opinativas

\begin{tabular}{|c|c|}
\hline Título & Data \\
\hline Reforma e competência (Editorial) & $30 / 12 / 2016$ \\
\hline Por um Brasil moderno e próspero (Artigo de opinião) & $25 / 04 / 2017$ \\
\hline Acordos poderão atenuar impacto da crise econômica (Análise) & $27 / 04 / 2017$ \\
\hline A reforma trabalhista é bem-vinda (Coluna) & $09 / 05 / 2017$ \\
\hline Vale o acordado (Editorial) & $15 / 07 / 2017$ \\
\hline
\end{tabular}

Definido e apresentado o corpus para investigação, passamos agora à análise dos textos.

\section{Análise dos textos}

A partir da observação e do exame atento dos fenômenos linguístico-textuais e discursivos manifestados nas publicações investigadas, dividimos a análise em duas partes, com o intuito de abordar separadamente dois eventos que nos chamaram a atenção. Ressaltamos que a segmentação da análise em dois subtópicos tem como objetivo único facilitar a compreensão dos fenômenos investigados.

\subsection{Sobre "acordos" e "negociações"}

Um primeiro exame dos textos nos revela o emprego recorrente das expressões nominais "acordo" e "negociação" para categorizar e recategorizar relações de 
trabalho, sobretudo nas publicações do grupo das notícias. Observemos, a princípio, os títulos das notícias que compõem o primeiro grupo. Dentre as cinco, em três aparecem os itens lexicais mencionados. Os grifos são nossos.

"Chefe do TST defende autonomia para negociações" (FSP, 25/12/2016);

"Reforma trabalhista inclui demissão em comum acordo" (FSP, 13/04/2017);

"Reajustes na crise indicam força de sindicato para negociar acordos" (FSP, 07/05/2017).

Conforme aponta Van Dijk (1996), as notícias são elaboradas com base numa estrutura top-down, na qual as informações consideradas mais relevantes pelo jornal são colocadas no início, ou seja, título, subtítulo e lide, enquanto as informações consideradas menos importantes são veiculadas nos últimos parágrafos. Além disso, o autor ainda aponta que os títulos das notícias têm função fundamental na compreensão sobre o fato abordado no texto, uma vez que eles sumarizam o que o jornal considera como as principais informações sobre o que está sendo noticiado.

A ocorrência das expressões nominais "acordo" e "negociação" não está restrita apenas aos títulos. Observamos que tais itens lexicais se apresentam também ao longo do texto das notícias, conforme podemos notar no exemplo (2), abaixo. Ressaltamos que empregamos o recurso negrito para indicar a introdução de um objeto de discurso e o recurso sublinhado e itálico para indicar a retomada de um mesmo objeto de discurso.

\section{(2) Reajustes na crise indicam força de sindicato para negociar acordos}

Os resultados obtidos nos sindicatos brasileiros na tentativa de preservar empregos e manter o poder de compra dos trabalhadores na atual recessão indicam que as entidades têm força para negociar acordos vantajosos para quem representam. Se a reforma trabalhista em debate no Congresso for aprovada, o que for definido nesses acordos em relação à jornada, banco de horas e intervalo para almoço, entre outras questões, poderá divergir ou se sobrepor à legislação. A mudança tem o apoio da Força Sindical e da UGT (Unidade Geral dos Trabalhadores), segunda e terceira maiores centrais do país. A maior delas, a CUT (Central Única dos Trabalhadores), defende o fortalecimento das negociações, mas não nos termos previstos no projeto em debate. Críticos da proposta dizem que esses acordos trarão mais perdas do que ganhos aos trabalhadores, diante da fraqueza dos sindicatos - agravada pelo fim do imposto sindical, também previsto na reforma. De acordo com o Dieese (Departamento Intersindical de Estatística e Estudos 
Socioeconômicos), a proporção de $\underline{\text { acordos }}$ que resultaram em perdas reais no ano passado ficou pouco acima de um terço do total $(36,7 \%)$.

(FSP, 07/05/2017)

No exemplo (2), notamos que o item lexical "acordos" foi empregado logo no título para introduzir um objeto de discurso e categorizar as relações que se constroem segundo o conceito de trabalho formulado na reforma trabalhista e reproduzido também no jornal. Mais adiante, no decorrer do texto, esse mesmo objeto de discurso é retomado novamente com o nome-núcleo "acordos", acrescido do qualificativo "vantajosos". Logo em seguida, as anáforas "nesses acordos", "esses acordos" e "acordos" recategorizam o mesmo referente.

Ressaltamos que há o emprego do item lexical "negociações” (em negrito, no texto), mas que tal expressão não se refere ao mesmo objeto de discurso mencionado anteriormente, uma vez que se trata de um tipo de relação de trabalho defendido pela CUT, que se opunha, por sua vez, à reforma trabalhista.

Compreendemos que, embora apresente a perspectiva de uma instituição contrária à reforma, o jornal emprega expressões nominais muito semelhantes às utilizadas no projeto para (re) categorizar as relações de trabalho. Ademais, entendemos que, ao utilizar o termo "acordo" de forma recorrente, o periódico elabora um conceito de trabalho no qual empregador e empregado gozam de igual poder de deliberação sobre as decisões que atravessam as relações de trabalho.

Koch (2015 [2002]) aponta que o uso contínuo de determinados itens ou expressões lexicais no processo de (re) categorização de um referente colabora para a elaboração e manutenção de um modelo de compreensão específico sobre atores, fatos e eventos do mundo. Nesse sentido, não parece ser aleatório o processo de referenciação apresentado no exemplo (2).

Salientamos, ainda, que o fato observado no exemplo anterior não é exclusivo do grupo de notícias, conforme é possível observar em trecho de um editorial, a seguir:

\section{(3) Vale o acordado}

[...] Controversa como qualquer iniciativa que envolva relações trabalhistas, a reforma se ampara em objetivos e princípios corretos. Reforça-se a autonomia de sindicatos e empresas para estabelecerem acordos coletivos, que prevalecerão sobre ditames da 
CLT. Assegurados direitos fundamentais, como férias e licença em caso de maternidade ou paternidade, patrões e empregados poderão negociar jornadas de trabalho, banco de horas e participação nos lucros, entre outras condições. As novas normas, que entrarão em vigor dentro de quatro meses, também ampliarão o leque de contratos possíveis. Tal flexibilidade oxigena uma legislação que remonta aos anos 1940. Não se está diante de uma panaceia, entretanto, nem de uma mudança sem riscos. A tutela do Estado sobre as relações trabalhistas, arraigada no país, deve ser superada de forma gradual - e não se descarte a correção de rotas mais à frente. Os acordos coletivos, por exemplo, pressupõem a existências de sindicatos de fato representativos para que os assalariados não fiquem desprotegidos [...].

(FSP, 15/07/2017).

No exemplo (3), é possível notar, novamente, o emprego do item lexical "acordo" para categorizar o conceito de trabalho veiculado no jornal. Primeiro, introduz-se o referente com o termo "acordado", no título. Em seguida, retoma-se o mesmo referente, recategorizando-o com as anáforas "acordos coletivos", "novas normas" e "contratos possíveis", ratificando, desse modo, o que havia sido observado no exemplo anterior.

Assumimos que, em ambos os exemplos analisados neste tópico, ocorre o que Fairclough (2001) denomina como tecnologização do discurso, isto é, o emprego de técnicas textuais-discursivas a fim de encobrir relações desiguais de poder. Entendemos que, ao empregar expressões como "acordo" e "negociações" recorrentemente para (re) categorizar as relações de trabalho, o jornal solapa a estrutura assimétrica na qual se assentam as relações trabalhistas, elaborando um modelo de compreensão sobre trabalho no qual empregador e empregado teriam iguais poderes de decisão.

Servindo-nos ainda do exemplo (3), chamamos a atenção também para outro fenômeno observado no decorrer da análise, a (re) categorização do conceito de trabalho elaborado na reforma como algo "moderno" e "flexível".

\subsection{Sobre "modernizações" e "flexibilizações"}

Notamos no exemplo (3) a ocorrência de uma anáfora que, embora não seja direta ou correferencial, aponta-nos um fenômeno interessante que repercute também em outras publicações. A expressão "tal flexibilidade" (sublinhada e sem itálico no texto) pode ser considerada uma anáfora encapsuladora, uma vez que ela retoma uma 
porção textual anterior, recategorizando-a com uma expressão nominal específica. Koch (2017 [2004]) afirma que as anáforas encapsuladoras, na medida em que retomam um trecho precedente do texto, lançam também sobre ele uma predicação que revela a perspectiva do interlocutor sobre o fato ou evento abordado.

Nesse sentido, entendemos que, ao comentar as relações de trabalho sugeridas pela reforma e apresentadas nos períodos precedentes do editorial, o jornal inicia um novo período no texto, recategorizando tais relações com o nome-núcleo "flexibilidade", inaugurando, por conseguinte, um posicionamento específico sobre o conceito de trabalho apresentado no projeto de lei.

A noção de que a reforma instaura relações de trabalho "flexíveis" e "modernas" reverbera ainda em outros textos, como é possível notar no exemplo (4).

\section{(4) Por um Brasil moderno e próspero}

[...] A modernização das leis do trabalho, ao oferecer mais liberdade e autonomia aos agentes, promoverá a formalização e ajudará na geração de empregos. Com a regulamentação do trabalho intermitente, poderemos formalizar, apenas no setor de bares e restaurantes, dois milhões de trabalhadores nos próximos três anos, segundo estimativa da Associação Brasileira de Bares e Restaurantes. Isso sem falar das consequências positivas da regulamentação do teletrabalho, já praticado por mais de 20 milhões de pessoas. Os que se valem de argumentos puramente ideológicos contra $\underline{a}$ modernização das leis prestam desserviço ao Brasil. Ao contrário do que dizem, $\underline{a}$ reforma não irá retirar direitos, uma vez que estes são protegidos pelo artigo $7^{\circ}$ da Constituição. A falácia é evidente, pois uma lei ordinária, como é o caso, não pode modificar Carta Magna. A modernização privilegia a resolução de conflitos por meio de entendimento direto entre empresários e trabalhadores [...].

(FSP, 25/04/2017).

No exemplo (4), o autor do artigo de opinião, o então deputado Rogério Marinho, categoriza a reforma como “a modernização das leis do trabalho”, lançando também sobre as relações de trabalho apresentadas no projeto uma perspectiva específica, assentada na "modernização" das práticas trabalhistas.

Ao longo do artigo, o deputado retoma o objeto de discurso introduzido com as anáforas "a regulamentação do trabalho intermitente", "a modernização das leis", "a reforma", "lei ordinária" e "a modernização", evidenciando, portanto, não só o aspecto legalista que a reforma abrange, mas também e, sobretudo, seu alinhamento com as necessidades contemporâneas do mundo do trabalho. 
Nesse ponto, retomamos o que Bourdieu (1998) aponta acerca da relação entre o neoliberalismo e o discurso sobre o trabalho. Conforme já discutido, segundo o autor, o mundo do trabalho é continuamente reconfigurado segundo as imposições e normas do mercado econômico, mais especificamente, neste caso, pelas práticas e discursos neoliberais. É nesse quadro que emergem igualmente discursos sobre "modernização" e "flexibilização" que visam a encobrir a precarização do trabalho.

\section{Considerações finais}

Sem sombra de dúvidas, o mundo do trabalho foi atravessado por mudanças significativas nos últimos anos. A emergência de um novo capitalismo aliada ao crescente processo de globalização contribuíram substancialmente para a manifestação de práticas e discursos neoliberais que operaram de modo nodal nas relações interpessoais e institucionais. Nesse quadro de reconfigurações, o conceito sobre trabalho também sofreu alterações. Uma pesquisa mais atenta revela que, em diversos países, surgiram propostas de reforma na legislação trabalhista, tendo como objetivo legalizar e legitimar relações de trabalho, muitas das vezes, deficientes e precárias para o trabalhador, deixando-o vulnerável judicialmente.

No Brasil, não ocorreu diferente. A reforma trabalhista, apresentada no final de 2016, visava, dentre muitos aspectos, a regulamentar relações de trabalho intermitente e desestruturar sindicatos trabalhistas através do fim da contribuição sindical obrigatória. Até ser sancionado pelo então presidente - e mesmo depois -, o projeto suscitou grande debate na mídia tradicional, a exemplo do jornal Folha de S.Paulo.

A partir da análise de 10 textos coletados na Folha, foi possível observar dois fenômenos relevantes para discussão. A princípio, notamos que o periódico ecoa o conceito de trabalho formulado na reforma na medida em que (re) categoriza as relações trabalhistas como "acordos" e "negociações". Entendemos que o emprego de tais termos opera na construção de um modelo de compreensão sobre o trabalho, no qual se apagam as relações assimétricas e desiguais em que estão inseridos empregador e empregado.

Além disso, observamos também que o jornal veicula textos, sobretudo de natureza opinativa, cujo objetivo consiste em (re) categorizar o conceito de trabalho 
formulado na reforma como um modelo de trabalho "moderno" e "flexível", portanto alinhado com as necessidades atuais do mercado.

Esperamos que esse artigo, longe de limitar as discussões, contribua com reflexões sobre a cobertura jornalística acerca de temas profundamente relevantes na vida dos cidadãos.

\section{REFERÊNCIAS}

APOTHÉLOZ, D. Papel e construção da anáfora na dinâmica textual. In: CAVAlCANTE, M. M; CIULlA, A; RODRIGUES, B. (orgs.). Referenciação. Contexto, São Paulo, 2005 [1995].

BAKHTIN, M. [VOLOCHINOV]. Marxismo e filosofia da linguagem. São Paulo: Hucitec, 2010 [1929].

BAUMAN, Z. Modernidade líquida. Rio de Janeiro: Zahar, 2001.

BOURDIEU, P. L'essence du néolibéralisme. Le monde diplomatique. Paris, p. 3, março de 1998. Disponível em: https://www.monde-diplomatique.fr/ 1998/03/BOURDIEU/3609. Acessado em: 10 de abril de 2020.

BRASIL. Projeto de lei $\mathrm{n}^{\circ}$ 6.787/2016. Dispõe sobre eleições de representantes dos trabalhadores em local de trabalho e sobre trabalho temporário e dá outras providências. Disponível

em: https://www.camara.leg.br/proposicoesWeb/fichadetramitacao?idProposicao=2122076. Acessado em: 08 de abril de 2020.

CAVALCANTE, M. M. Expressões referenciais: uma proposta classificatória. Caderno de estudos Linguísticos, Campinas, v. 44, p. 105-118, jan./jun., 2003. Disponível em: https://periodicos.sbu.unicamp.br/ojs/index.php/cel/article/view/8637068. Acessado em: 10 de abril de 2020.

CHOULIARAKI, L; FAIRCLOUGH, N. Discourse in late modernity: rethinking critical discourse analysis. Edinburgh: University Press. 1999. 
CIULLA, A. Os processos de referência e suas funções discursivas - o universo literário dos contos. Tese (Doutorado). Universidade Federal do Ceará, Fortaleza, 2008.

FAIRCLOUGH, N. Discurso e mudança social. Brasília: Editora UnB, 2001.

FAIRCLOUGH, N. Discourse, social theory and social research: the discourse of welfare reform. Journal of sociolinguistic. New Jersey. V. 4, issue 2, p. 165-195, dezembro de 2002. Disponível em: https://onlinelibrary.wiley.com/doi/10.1111/14679481.00110. Acessado em: 10 de abril de 2020.

FAIRCLOUGH, N. Analysing discourse: textual analysis for social research. London: Routledge, 2003.

KOCH, I. As tramas do texto. São Paulo: Contexto 2014.

KOCH, I. Desvendando os segredos do texto. São Paulo: Cortez 2015 [2002].

KOCH, I. Introdução à linguística textual: trajetória e grandes temas. São Paulo: Contexto, 2017 [2004].

KOCH, I; MARCUSCHI, L. A. Processos de referenciação na produção discursiva. DELTA, v. 14, p. 169-190 (número especial), 1998. Disponível em: http://www.scielo.br/scielo.php?script=sci_arttext\&pid=S010244501998000300012\&ln $\mathrm{g}=\mathrm{pt} \&$ tlng=pt. Acessado em: 10 de abril de 2020.

LAKOFF, G. Women, fire and dangerous things: what categories reveal about the mind. Chicago and London: The University of Chicago Press, 1987.

MARCUSCHI, L. A. Cognição, linguagem e práticas interacionais. Rio de Janeiro: Lucerna, 2007.

MARCUSCHI, L. A. Referenciação e progressão tópica: aspectos cognitivos e textuais. Cadernos de Estudos Linguísticos, Campinas, v. 48, n 1, p. 7-22, 2006. Disponível em: https://periodicos.sbu.unicamp.br/ojs/index.php/cel/article/view/8637251. Acessado em: 09 de abril de 2020.

MONDADA, L; DUBOIS, D. Construção dos objetos de discurso e categorização: uma abordagem dos processos de referenciação. In: CAVALCANTE, M. M; CIULLA, A; RODRIGUES, B. (orgs.). Referenciação. São Paulo: Contexto, 2005 [1995].

VAN DIJK, T. Cognição, discurso e interação. São Paulo: Contexto, 1996. 
Revista Moara, n. 58, jan-jul 2021 ISSN: 0104-0944 